\title{
Pacing for neurally-mediated syncope: How to decide?
}

\author{
Michele Brignole \\ Arrhythmologic Center, Department of Cardiology, Ospedali del Tigullio, Lavagna, Italy
}

\begin{abstract}
Neurally-mediated syncope has a broad clinical spectrum which ranges from typical vasovagal syncope on one hand, to those situations in which reflex syncope occurs with uncertain, or even apparently absent, triggers or prodromes, on the other hand. Overlap of clinical features is frequent in clinical practice and makes any classification difficult to apply when selecting patients for cardiac pacing. Typically, the reflex is both hypotensive and cardio-inhibitory. The rationale for efficacy of cardiac pacing is that the cardio-inhibitory reflex is dominant, since there is no role for pacing in preventing vasodilatation and hypotension. Establishing a relationship between symptoms and cardio-inhibitory reflex should be the goal of the clinical evaluation before embarking on permanent pacing. Similar efficacy has been observed in patients affected by dominant cardio-inhibitory reflex irrespective of the clinical form. In general, cardiac pacing should be considered last choice applied only in highly selected patients, i.e. those $\geq 40$ years of age, affected by severe forms of reflex syncope with recurrences associated with frequent injury, often due to the lack of prodromes. Recurrence of syncope may still occur despite cardiac pacing in a minority of patients. (Cardiol J 2014; 21, 6: 601-605)
\end{abstract}

Key words: syncope, carotid sinus syndrome, implantable loop recorder, tilt table test, adenosine, prolonged monitoring

\section{Evidence from the trials in patients with tilt-induced vasovagal syncope}

Effectiveness of pacing in tilt-induced vasovagal syncope patients has been studied in 5 multi-center randomized clinical trials [1-5]; 3 non-blinded trials gave positive results and 2 blinded trials gave negative results. Adding together the results of the 5 trials, 318 patients were evaluated; syncope recurred in $21 \%$ of the paced patients and in $44 \%$ of unpaced patients $(\mathrm{p}<0.001)$. A recent meta-analysis of all studies suggested a non-significant $17 \%$ reduction in syncope from the double-blinded studies, and an $84 \%$ reduction in the studies where the control group did not receive a pacemaker (PM) [6].

All these studies have their limitations. A comparison of these studies causes slight difficulties because of important differences in study design, largely focused on patient selection. Overall, in typical vasovagal population pacing seems to have marginal efficacy. These findings suggest caution in implanting a PM based on the tilt response.

Typically, the vasovagal reflex is both hypotensive and cardioinhibitory. The rationale for efficacy of cardiac pacing is that the cardio-inhibitory reflex is dominant in some patients, since there is no role for pacing in preventing vasodilatation and hypotension. While there is a growing skepticism over diagnostic accuracy of tilt testing (TT) for syncope diagnosis, emerging evidence support the use of tilt table testing in assessing susceptibility to reflex hypotension [7]. In this study it is discussed how to decide who can benefit from pacing when vasovagal syncope is present.

Address for correspondence: Michele Brignole, MD, FESC, Arrhythmologic Center, Department of Cardiology, Ospedali del Tigullio, Via Don Bobbio 25, 16033 Lavagna, Italy, tel: 0185 329569, fax: 0185 306506, e-mail: mbrignole@ASL4.liguria.it 


\section{Evidence from the trials in patients with suspected or certain vasovagal (reflex) syncope and electrocardiogram- -documented asystole}

In 2 observational studies, cardiac pacing reduced syncope burden in patients with documented asystolic syncope by $92 \%$ [8] and by $83 \%$ [9], respectively, but did not prevent all syncopal events. In the randomized, double-blind, Third International Study on Syncope of Uncertain Etiology (ISSUE-3) trial [10], 511 patients $\geq 40$ years with recurrent reflex syncope received an implantable loop recorder (ILR); 89 of them had documentation of syncope with $\geq 3$ s asystole or $\geq 6$ s asystole without syncope within $12 \pm 10$ months, and met criteria for PM implantation; 77 of 89 patients were randomly assigned to dual-chamber pacing with rate drop response or to sensing only. The data were analyzed on an intention-to-treat principle. During the follow-up, the 2-year estimated syncope recurrence rate was $57 \%$ with $\mathrm{PM} \mathrm{OFF}$ and $25 \%$ with PM ON (log-rank $\mathrm{p}=0.039$ ). The risk of recurrence was reduced by $57 \%$.

The ISSUE studies focused on subjects affected by reflex syncope with a mean age of 63 years, a history of recurrent syncope beginning in middle or older age and frequent injuries probably due to lack of a prodrome. Young patients were not included in the ISSUE population because they usually have a more prolonged prodrome before loss of consciousness. Although ISSUE-3 proved the efficacy of cardiac pacing in highly selected patients, the patients who had received pacing therapy still had an estimated syncopal recurrence rate of $25 \%$ at 2 years. In ISSUE-3, only about half of the patients had a positive TT.

A recent sub-analysis of ISSUE-3 [11] showed that syncope recurrence rate was $5 \%$ in those patients who had negative TT and 55\% in those who had a positive TT $(p=0.004)$. The recurrence rate of patients with positive TT was similar to that observed in controls without pacing. Syncope recurrence was independent of the type of response during TT. Although an asystolic response during TT predicted spontaneous asystole with an accuracy of $86 \%$, the study was unable to show a benefit greater than in the patients with non-asystolic responses.

Before ISSUE-3, cardiac pacing for reflex syncope had only been evaluated in patients with a positive TT; no indication for pacing in patients with negative TT existed. By showing that tilt-negative patients are those who benefit most from cardiac pacing, ISSUE-3 inverts previous assumption on indications for pacing. The observed 5\% recurrence rate with pacing is similar to that observed in patients paced for intrinsic bradycardia. Thus, PM therapy might be offered to these patients with the same confidence as in patients with intrinsic sinus node disease or atrioventricular (AV) block.

Similarly, in carotid sinus syndrome patients who also had positive TT there was 2.7-fold greater syncope recurrence probability after dual chamber pacing than in those with negative TT [12]. In these 2 types of reflex syncope, when tilt-testing is positive caution should be recommended over PM implantation. However, the above results are based on a single sub-study whose findings cannot be taken as conclusive and need to be confirmed by other studies before they are accepted in the clinical practice.

\section{Evidence from the trials in patients with carotid sinus syndrome}

The evidence supporting the benefit of cardiac pacing in patients affected by carotid sinus syncope (CSS) is limited to few small controlled trials and retrospective observational studies. In a MedLine search among peer-review journals in English language of the articles dealing with natural and unnatural history of CSS (case reports excluded), 12 studies reported sufficient follow-up data for analysis. In total, they reported the natural history up to 5 years of follow-up of 305 patients and the effect of cardiac pacing on other 601 patients affected by severe recurrent syncope [13].

The studies were largely heterogeneous with regard to selection of patients, duration and position (supine or standing) of the carotid sinus massage, criteria for identification of mixed forms of carotid sinus syndrome and different mode of pacing (single- vs. dual-chamber). In general, with pacing, syncopal recurrence rate during the follow-up ranged between $0 \%$ and $20 \%$, whereas the recurrence of syncope was always higher in untreated patients who showed a rate between $20 \%$ and $60 \%$. In a meta-analysis of 3 studies [14-16] with a control group of untreated patients, syncope recurred in $9 \%$ of 85 patients treated with $\mathrm{PM}$ and in $38 \%$ of 91 controls (relative risk $=0.24 ; 95 \% \mathrm{CI}$ 0.12-0.48). In a large registry of 169 consecutive patients treated with PM, the actuarial estimate of syncopal recurrence was $7 \%$ at 1 year, $16 \%$ at 3 years and $20 \%$ at 5 years [17].

Two variables are well known to hamper the efficacy of pacing therapy in CSS patients. These are mixed forms and the association with positivity 
of TT of carotid sinus syndrome. Due to lack of a standardized methodology of execution of the carotid sinus massage, the prevalence of mixed forms shows a great variability among different studies. The prevalence of mixed forms was higher in those studies in which the massage was prolonged $\geq 10 \mathrm{~s}$ and performed in standing position, and also when the magnitude of the vasodepressor component was assessed after suppression of the cardioinhibitory component by i.v. atropine [14, 18-21]. For patients who had positive TT (bradycardia and hypotension), there was a 2.7 -fold greater syncope recurrence probability after dual chamber pacing than in those with negative TT [21]. When tilttesting is positive, caution must be recommended over PM implantation.

In conclusion, cardiac pacing is effective in preventing recurrences of syncope in CSS patients, but syncopal recurrence is expected to occur in up to $20 \%$ of patients within 5 years.

\section{Evidence from the trials in patients with adenosine-sensitive syncope}

Common clinical features characterize "low adenosine syncope" which has been recently described in patients who have an otherwise unexplained syncope with sudden onset without prodromes and a normal heart and normal electrocardiogram (ECG). These patients typically have a low plasma adenosine value below $0.36 \mathrm{mmol} / 1$ (normal values in healthy subjects range $0.32-2.80 \mathrm{mmol} / \mathrm{l}$ ) and show an increased susceptibility to exogenous adenosine injection, i.e., adenosine triphosphate and adenosine tests. In those patients in whom a spontaneous ECG could be recorded at the time of a spontaneous syncope, the ECG showed paroxysmal AV block with one or multiple consecutive pauses, without P-P cycle lengthening or PR interval prolongation. In these patients, cardiac pacing was very effective in preventing syncopal recurrences $[22,23]$.

The role of the adenosine triphosphate and adenosine tests is controversial in identifying such patients. Three studies showed no correlation between AV block induced by adenosine triphosphate and ECG findings (documented by ILR) during spontaneous syncope [24-26]. Thus, the low predictive value of the test does not support its use as a solitary diagnostic test for selecting patients for cardiac pacing. In a small multi-center trial [27], performed on 80 highly selected elderly patients with unexplained syncope who had a positive response to intravenous injection of a bolus of $20 \mathrm{mg}$ of adenosine triphosphate, dual-chamber cardiac pacing significantly reduced 2 -year syncopal recurrence from $69 \%$ in the control group to $23 \%$ in the active group with an estimated proportional hazard ratio of 0.25 (95\% CI $0.12-0.56)$.

\section{Choice of pacing mode}

Dual-chamber pacing was used in almost all trials with a rate drop response feature of the PM that instituted rapid DDD pacing if the device detected a rapid decrease in heart rate, but no comparison with conventional dual-chamber pacing was ever made. No comparison with VVI pacing was performed. In the absence of comparative studies, the Task Force of the European Society of Cardiology was unable to make an evidence-based specific recommendation on the choice of pacing mode. Nevertheless, this Task Force believes that dual-chamber should be preferred over single-chamber ventricular pacing in order to avoid the risk of PM syndrome caused by the latter modality [28].

\section{Conclusions}

\section{Pacing for neurally-mediated syncope: How to decide?}

It must be emphasized that the decision to implant a PM needs to be undertaken in the clinical context that is a benign, not life-threatening condition. The condition typically affects young patients (for whom there is little systematic evidence for pacing). The fact that pacing is effective in some patients with reflex syncope does not mean that it is always necessary. A placebo effect has also been suggested as the apparent cause for benefit in some patients. Nevertheless, for a highly symptomatic patient with recurrent and frequent asystolic reflex syncope, for whom the evidence of concomitant hypotension is not substantiated, pacing may be considered an option.

However, in patients with reflex syncope, cardiac pacing should be the last therapeutic choice after other options are tried and should only be considered in highly selected patients, i.e. those $\geq 40$ years of age, affected by severe forms of reflex syncope with recurrences associated with frequent injury, often due to the lack of prodrome. It is likely that younger patients who have syncope preceded by prodromes would not benefit from PM therapy to the same extent; pacing should be avoided with very few exceptions. The decision tree reported in Figure 1 is a practical algorithm which summarizes the available data from the trials. 


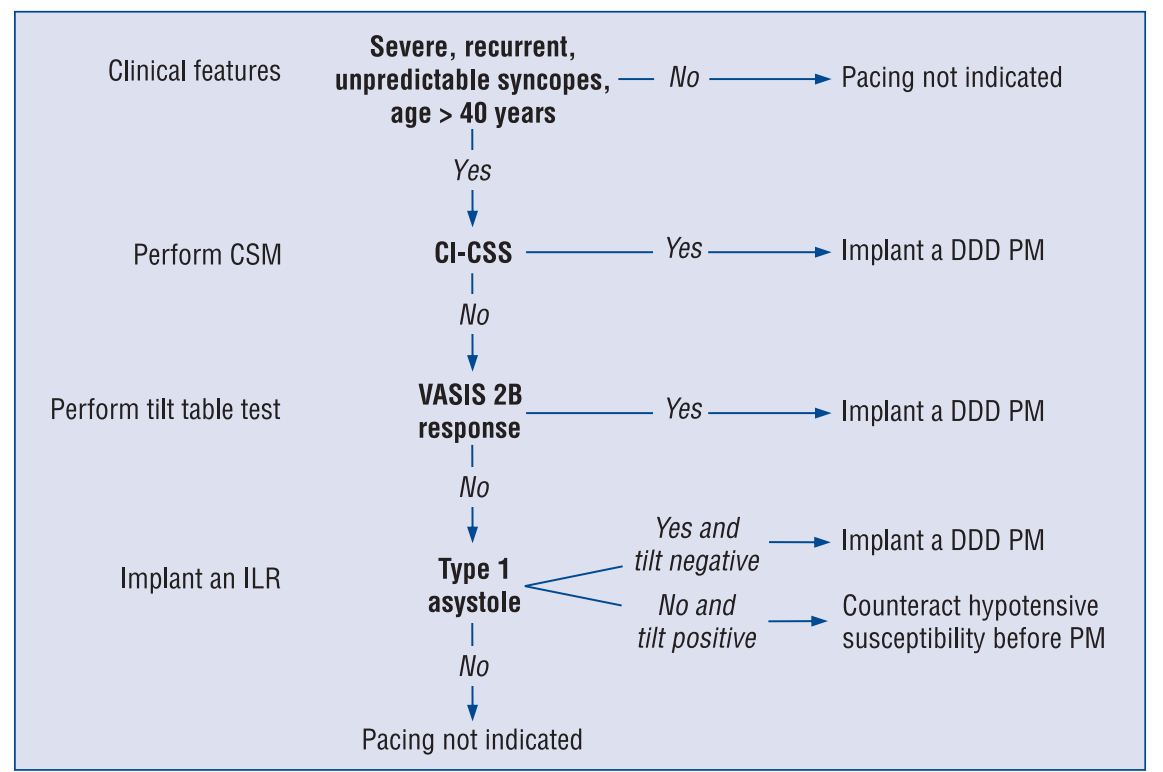

Figure 1. Pacing for neurally-mediated syncope: decision tree; CSM - carotid sinus massage; CI-CSS - cardioinhibitory carotid sinus syndrome; ILR — implantable loop recorder; PM — pacemaker.

\section{Conflict of interest: None declared}

\section{References}

1. Connolly SJ, Sheldon R, Roberts RS, Gent M. The North American Vasovagal Pacemaker Study (VPS). A randomized trial of permanent cardiac pacing for the prevention of vasovagal syncope. J Am Coll Cardiol, 1999; 33: 16-20.

2. Sutton R, Brignole M, Menozzi C et al. Dual-chamber pacing in the treatment of neurally mediated tilt-positive cardio-inhibitory syncope: Pacemaker versus no therapy: A multicenter randomized study. The Vasovagal Syncope International Study (VASIS) Investigators. Circulation, 2000; 102: 294-299.

3. Ammirati F, Colivicchi F, Santini M. Permanent cardiac pacing versus medical treatment for the prevention of recurrent vasovagal syncope: A multicenter, randomized, controlled trial. Circulation, 2001; 104: 52-57.

4. Connolly SJ, Sheldon R, Thorpe KE et al. Pacemaker therapy for prevention of syncope in patients with recurrent severe vasovagal syncope: Second Vasovagal Pacemaker Study (VPS II): a randomized trial. JAMA, 2003; 289: 2224-2229.

5. Raviele A, Giada F, Menozzi C et al. A randomized, double-blind, placebo-controlled study of permanent cardiac pacing for the treatment of recurrent tilt-induced vasovagal syncope. The vasovagal syncope and pacing trial (SYNPACE). Eur Heart J, 2004; 25: 1741-1748.

6. Sud S, Massel D, Klein GJ et al. The expectation effect and cardiac pacing for refractory vasovagal syncope. Am J Med, 2007; 120: 54-62.

7. Sutton R, Brignole M. Twenty-eight years of research permit reinterpretation of tilt-testing: Hypotensive susceptibility rather than diagnosis. Eur Heart J, 2014; 35: 2211-2212.

8. Brignole M, Sutton R, Menozzi C et al. Early application of an implantable loop recorder allows effective specific therapy in patients with recurrent suspected neurally mediated syncope. Eur Heart J, 2006; 27: 1085-1092.
9. Sud S, Klein GJ, Skanes AC, Gula LJ, Yee R, Krahn AD. Implications of mechanism of bradycardia on response to pacing in patients with unexplained syncope. Europace, 2007; 9: 312-318.

10. Brignole M, Menozzi C, Moya A et al. Pacemaker therapy in patients with neurally mediated syncope and documented asystole: Third International Study on Syncope of Uncertain Etiology (ISSUE-3): a randomized trial. Circulation, 2012; 125: 2566-2571.

11. Brignole M, Donateo P, Tomaino $\mathrm{M}$ et al. Benefit of pacemaker therapy in patients with presumed neurally mediated syncope and documented asystole is greater when tilt test is negative: An analysis from the Third International Study on Syncope of Uncertain Etiology (ISSUE-3). Circ Arrhythm Electrophysiol, 2014; 7: 10-16.

12. Gaggioli G, Brignole M, Menozzi $C$ et al. Positive response to head-up tilt testing predicts syncopal recurrence in carotid sinus syndrome patients with permanent pacemakers. Am J Cardiol, 1995; 76: 720-722.

13. Brignole $\mathrm{M}, \mathrm{Menozzi} \mathrm{C}$. The natural history of carotid sinus syncope and the effect of cardiac pacing. Europace, 2011; 13: 462-464.

14. Brignole M, Menozzi C, Lolli G, Bottoni N, Gaggioli G. Long-term outcome of paced and nonpaced patients with severe carotid sinus syndrome. Am J Cardiol, 1992; 69: 1039-1043.

15. Claesson JE, Kristensson BE, Edvardsson N, Währborg P. Less syncope and milder symptoms in patients treated with pacing for induced cardioinhibitory carotid sinus syndrome: A randomized study. Europace, 2007; 9: 932-936.

16. Sugrue D, Gersh B, Holmes D, Wood D, Osborn M, Hammill S. Symptomatic "isolated" carotid sinus hypersensitivity: Natural history and results of treatment with anticholinergic drugs or pacemaker. J Am Coll Cardiol, 1986; 7: 158-162.

17. Gaggioli G, Brignole M, Menozzi C et al. Positive response to head-up tilt testing predicts syncopal recurrence in carotid sinus syndrome patients with permanent pacemakers. Am J Cardiol, 1995; 76: 720-722.

18. Brignole M, Sartore B, Barra M, Menozzi C, Lolli G. Ventricular and dual chambre pacing for treatment of carotid sinus syndrome. Pacing Clin Electrophysiol, 1989; 12: 582-590. 
19. Solari D, Maggi R, Oddone D et al. Clinical context and outcome of carotid sinus syndrome diagnosed by means of the "method of symptoms”. Europace, 2014; 16: 928-934.

20. Solari D, Maggi R, Oddone D et al. Assessment of the vasodepressor reflex in carotid sinus syndrome. Circ Arrhythm Electrophysiol, 2014; 7: 505-510.

21. Gaggioli G, Brignole M, Menozzi C et al. A positive response to head-up tilt testing predicts syncopal recurrence in carotid sinus syndrome patients with permanent pacemakers. Am J Cardiol, 1995; 76: 720-722.

22. Brignole M, Deharo JC, De Roy L et al. Syncope due to idiopathic paroxysmal atrioventricular block: Long-term follow-up of a distinct form of atrioventricular block. J Am Coll Cardiol, 2011; 58: 167-173.

23. Deharo JC, Guieu R, Mechulan A et al. Syncope without prodromes in patients with normal heart and normal electrocardiogram: A distinct entity. J Am Coll Cardiol, 2013; 62: 1075-1080.

24. Donateo P, Brignole M, Menozzi C et al. Mechanismof syncope in patients with positive adenosine triphosphate tests. J Am Coll Cardiol, 2003; 41: 93-98.
25. Deharo JC, Jego C, Lanteaume A, Djiane P. An implantable loop recorder study of highly symptomatic vasovagal patients: The heart rhythm observed during a spontaneous syncope is identical to the recurrent syncope but not correlated with the head-up tilt test or adenosine triphosphate test. J Am Coll Cardiol, 2006;47: 587-593.

26. Brignole M, Sutton R, Menozzi C et al. Lack of correlation between the responses to tilt testing and adenosine triphosphate test and the mechanism of spontaneous neurally mediated syncope. Eur Heart J, 2006; 27: 2232-2239.

27. Flammang D, Church TR, De Roy L et al. Treatment of unexplained syncope: A multicenter, randomized trial of cardiac pacing guided by adenosine 5 '-triphosphate testing. Circulation, 2012; 125: 31-36.

28. Brignole M, Auricchio A, Baron-Esquivias G et al. 2013 ESC guidelines on cardiac pacing and cardiac resynchronization therapy: The task force on cardiac pacing and resynchronization therapy of the European Society of Cardiology (ESC). Developed in collaboration with the European Heart Rhythm Association (EHRA). European Society of Cardiology (ESC); European Heart Rhythm Association (EHRA). Eur Heart J, 2013; 34: 2281-2329. 